\title{
PREVALENCE OF EXTENDED SPECTRUM BETA-LACTAMASES AND AMP-C BETA-LACTAMASES IN CLINICAL ISOLATES OF GRAM-NEGATIVE BACILLI AT A TERTIARY CARE HOSPITAL
}

\author{
Malini Jagannatha Rao', Shruthi Harle2, Padmavathy M$^{3}$
}

${ }^{1}$ Specialist cum Assistant Professor, Department of Microbiology, ESIC-MC-PGIMSR, Bangalore, Karnataka, India.

${ }^{2}$ Specialist, Department of Microbiology, ESIC-MC-PGIMSR, Bangalore, Karnataka, India.

${ }^{3}$ Specialist cum Assistant Professor, Department of Microbiology, ESIC-MC-PGIMSR, Bangalore, Karnataka, India.

\section{ABSTRACT}

\section{BACKGROUND}

Amp-C beta-lactamase are cephalosporinases that hydrolyze cephamycins as well as other extended spectrum cephalosporins and are poorly inhibited by clavulanic acid. Although, reported with increasing frequency, the true rate of occurrence of Amp-C $\beta$ lactamases in different organisms including members of Enterobacteriaceae remains unknown.

The present study was designed to determine the occurrence of Extended Spectrum Beta-Lactamases (ESBL) and Amp-C betalactamase enzyme harbouring Gram-negative clinical isolates in a tertiary care hospital in South India.

\section{MATERIALS AND METHODS}

A total of 205 Gram-negative bacteria were screened for ESBL and Amp-C beta-lactamases. Isolates found to be positive by the screening test were subjected to the confirmatory test for ESBL and Amp-C disk test for plasmid Amp-C production.

\section{RESULTS}

Of the 205 clinical isolates, 135 (65.9\%) were screen test positive for ESBL. Confirmatory test for ESBL revealed 79 (38.5\%) isolates to be positive and 71 isolates were screen test positive for Amp-C beta-lactamase. Plasmid Amp-C was detected in 32 (15.6\%) by Amp-C disc test. Co-production of ESBL and Amp-C was seen in 9 (4.4\%) isolates and maximum coexistence was seen in Klebsiella pneumoniae (15.3\%) isolates.

\section{CONCLUSION}

Screening and confirmatory tests are necessary to identify ESBL and true Amp-C producers, as it is a simple and rapid procedure. The high incidence of beta-lactamase production due to multiple mechanisms is alarming and requires urgent action from both a therapeutic and infection control perspective, so that proper antibiotic policy and appropriate measures could be taken to restrict the indiscriminate use of cephalosporins and carbapenems, so as to minimise the emergence of this multiple beta-lactamase producing organisms.

\section{KEY WORDS}

Gram-Negative Bacilli, Extended Spectrum Beta-Lactamase, Amp-C Beta-Lactamase, Amp-C Disk Test, Third Generation Cephalosporins.

HOW TO CITE THIS ARTICLE: Rao MJ, Harle S, Padmavathy M. Prevalence of extended spectrum beta-lactamases and amp-C betalactamases in clinical isolates of gram-negative bacilli at a tertiary care hospital. J. Evolution Med. Dent. Sci. 2018;7(39):4272-4276, DOI: $10.14260 /$ jemds/2018/953

\section{BACKGROUND}

Resistant bacteria are emerging worldwide as a threat to favourable outcome in the treatment of common infections in community and settings. Among the wide array of antibiotics, ß-lactams are the most widely used agents. ${ }^{1}$ The predominant mechanism for resistance to beta-lactam antibiotics in Gram-negative bacteria is by the synthesis of beta-lactamase. Among the beta-lactamase, the production of Extended Spectrum Beta-Lactamase (ESBL) and Amp-C betalactamase are the most common. ${ }^{2}$

ESBLs are enzymes manifesting considerable hydrolytic activity on a wide variety of beta-lactam antibiotics including oxyimino-cephalosporins and aztreonam, and are inhibited

'Financial or Other Competing Interest': None.

Submission 23-02-2018, Peer Review 10-09-2018,

Acceptance 17-09-2018, Published 24-09-2018.

Corresponding Author:

Malini Jagannatha Rao,

Specialist cum Assistant Professor,

Department of Microbiology, ESIC-MC-PGIMSR,

Rajajinagar, Bangalore, Karnataka, India.

E-mail: malinirao74@gmail.com

DOI: $10.14260 /$ jemds $/ 2018 / 953$

\section{(c) $(i)$}

by clavulanic acid. ${ }^{3}$ Many laboratories have adopted Clinical Laboratory Standard Institute (CLSI) recommendation and only attempted to detect ESBLs in Escherichia coli, Klebsiella pneumoniae, K. oxytoca and Proteus mirabilis. Since ESBL genes are transmissible, it is important that ESBLs be tested for in other organisms in hospital and long-term care facility patient populations where ESBLs are encountered. ${ }^{4}$

Amp-C class beta-lactamases are cephalosporinases that are poorly inhibited by clavulanic acid. They can be differentiated from other ESBLs by their ability to hydrolyze cephamycins as well as other extended spectrum cephalosporins. $^{5}$ Genes for Amp-C $\beta$-lactamases are commonly found on the chromosomes of the several members of the family Enterobacteriaceae including Enterobacter, Shigella, Providencia, Citrobacter freundii, Morganella morganii, Serratia marcescens and Escherichia coli. Plasmid mediated Amp-C $\beta$-lactamases has arisen through the transfer of chromosomal genes for the inducible Amp-C $\beta$-lactamases onto plasmids. The transfer has resulted in plasmid mediated Amp-C $\beta$-lactamases in isolates of Escherichia coli, Klebsiella pneumoniae, Salmonella species, Citrobacter freundii, Enterobacter aerogenes and Proteus mirabilis. ${ }^{6}$ Unlike chromosome-mediated Amp-C, plasmid- 
encoded Amp-C enzymes are almost always expressed constitutively. ${ }^{2}$ Plasmid-mediated Amp-C are associated with potentially fatal errors of false susceptibility on routine susceptibility tests.?

Amp-C producing organisms act as hidden reservoir for ESBLs. Their co-existence further complicates the picture, because high level expression of Amp-C $\beta$-lactams may mask the recognition of ESBLs. Although reported with increasing frequency, the true rate of occurrence of Amp-C $\beta$-lactamases in different organisms including members of Enterobacteriaceae remains unknown. The current Clinical Laboratory Standards Information (CLSI) guidelines do not describe any method for detection of isolates producing AmpC $\beta$-lactamases.

The present study was designed to investigate the presence of ESBLs and Amp-C beta-lactamase enzymes and their co-production in clinical isolates of gram-negative bacilli from a tertiary care hospital.

\section{MATERIALS AND METHODS}

This descriptive study was carried out at Employees State Insurance Corporation Medical College and Postgraduate Institute of Medical Sciences and Research (ESICMC-PGIMSR), a tertiary care hospital between April 2011 and June 2011. A total of 205 consecutive non-repeat culture clinical isolates were obtained from various clinical specimens (Table 1), such as urine 88 (42.9\%), pus/ wound swab 57 (27.8\%), sputum 30 (14.6\%), blood 21 (10.2\%), stools 06 (2.9\%) and miscellaneous samples $03(1.4 \%)$ from both inpatient and outpatients. All the isolates were identified as per recommended procedure. ${ }^{8}$

Antimicrobial susceptibility testing was carried out with Kirby-Bauer's disc diffusion method. ${ }^{9}$ Antibiotic discs used were amoxycillin/ clavulanic acid $(20 / 10 \mu \mathrm{g})$, piperacillintazobactam $(100 / 10 \mu \mathrm{g})$, gentamicin $(10 \mu \mathrm{g})$, amikacin $(30 \mu \mathrm{g})$, ciprofloxacin $(5 \mu \mathrm{g})$, trimethoprim-sulfamethoxazole $(1.25 / 23.75 \mu \mathrm{g})$, ceftazidime $(30 \mu \mathrm{g})$, ceftriaxone $(30 \mu \mathrm{g})$, cefotaxime $(30 \mu \mathrm{g})$, cefoxitin $(30 \mu \mathrm{g})$, imipenem $(10 \mu \mathrm{g})$ and cefuroxime $(30 \mu \mathrm{g})$. The zone diameters were interpreted as per the CLSI recommendations. ${ }^{10}$ Escherichia coli ATCC 25922 strains was used for quality control.

\section{Screening Test for ESBLs}

According to the CLSI guidelines, isolates showing inhibition zone size of $\leq 22 \mathrm{~mm}$ with ceftazidime ( $30 \mu \mathrm{g}), \leq 25 \mathrm{~mm}$ with ceftriaxone $(30 \mu \mathrm{g})$ and $\leq 27 \mathrm{~mm}$ with cefotaxime $(30 \mu \mathrm{g})$ were identified as potential ESBL producers and shortlisted for confirmation of ESBL production. ${ }^{11}$

\section{Confirmatory Tests for ESBLs}

Phenotypic confirmatory test with combination disk (Figure1). This test requires the use of a third-generation cephalosporin antibiotic disk alone and in combination with clavulanic acid. In this study, a disk of Ceftazidime $(30 \mu \mathrm{g})$ alone and a disk of Ceftazidime + Clavulanic acid (30 $\mu \mathrm{g} / 10$ $\mu \mathrm{g})$ were used. Both the disks were placed at least $25 \mathrm{~mm}$ apart, center-to-center, on a lawn culture of the test isolate on Mueller-Hinton Agar (MHA) plate and incubated overnight at $37^{\circ} \mathrm{C}$. Difference in zone diameters with and without clavulanic acid was measured.

Interpretation: When there is an increase of $\geq 5 \mathrm{~mm}$ in inhibition zone diameter around combination disk of
Ceftazidime + Clavulanic acid versus the inhibition zone diameter around Ceftazidime disk alone, it confirms ESBL production.

\section{Screening Test for Amp-C}

Isolates showing reduced susceptibility to either of these drugs (ceftazidime or cefotaxime) and cefoxitin.

\section{Detection of Plasmid-Mediated Amp-C Production Amp-C Disk Test}

The test is based on use of Tris-EDTA to permeabilize a bacterial cell and release $\beta$-lactamases into the external environment. Amp-C disks (i.e. filter paper disks containing Tris-EDTA) were prepared in-house by applying $20 \mu \mathrm{L}$ of a 1:1 mixture of saline and 100x Tris-EDTA to sterile filter paper disks, allowing the disks to dry and storing them at 2 to $8^{\circ} \mathrm{C}$. The surface of a Mueller-Hinton agar plate was inoculated with a lawn of cefoxitin susceptible E. coli ATCC 25922 according to the standard disk diffusion method. Immediately, prior to use Amp-C disks were rehydrated with $20 \mu \mathrm{L}$ of saline and several colonies of each test organism were applied to a disk. A $30 \mu \mathrm{g}$ cefoxitin disk was placed on the inoculated surface of the Mueller-Hinton agar. The inoculated Amp-C disk was then placed almost touching the antibiotic disk with the inoculated disk face in contact with the agar surface. The plate was then inverted and incubated overnight at $35^{\circ} \mathrm{C}$ in ambient air. After incubation, plates were examined for either an indentation or a flattening of the zone of inhibition indicating enzymatic inactivation of cefoxitin (positive result) or the absence of a distortion indicating no significant inactivation of cefoxitin (negative result) (Figure-2).

\section{RESULTS}

A total of 205 consecutive non-repeat culture clinical isolates of Escherichia coli $(n=87)$, Acinetobacter spp. $(n=29)$, Pseudomonas aeruginosa $(n=27)$, Klebsiella pneumoniae $(n=26)$, Salmonella typhi $(n=13)$, Enterobacter spp. $(n=6)$, Proteus mirabilis $(n=5)$, Vibrio cholerae $(n=5)$, Providencia spp. $(n=3)$, Citrobacter spp. $(n=2)$ and Shigella spp. $(n=2)$ were included in the study. The number of potential ESBL and Amp-C $\beta$-lactamase producers detected by the screening test were 135 and 71 isolates respectively.

\section{ESBL Production}

Out of the 205 total isolates tested, 135 (65.9\%) isolates were resistant to 3GC. ESBL production was seen in 79 (38.5\%) of the total isolates. Of the total isolates $56 \%$ of Pseudomonas aeruginosa $n=14,50.6 \%$ of E. coli $n=44,46.1 \%$ of Klebsiella spp. $n=12$ and $25.8 \%$ of Acinetobacter $n=8$ were found to be ESBL positive (Table 2).

\section{Amp-C Enzyme Production}

Of the 205 isolates, 71 showed resistance to either of these drugs (ceftazidime or cefotaxime) and cefoxitin (Table-3) were considered as presumptive Amp-C producers and further confirmed by Amp-C disk test.

\section{Amp-C Disk Test}

By Amp-C disk test, 32 (15.6\%) isolates showed plasmid Amp-C positive, Table 2. 


\section{ESBL and Amp-C Coexistence}

This study demonstrated the co-existing phenotypes of both ESBL and Amp-C in 9 (4.4\%) isolates, which was noted in Escherichia coli 5 (5.7\%) and Klebsiella pneumoniae 4 (15.3\%).

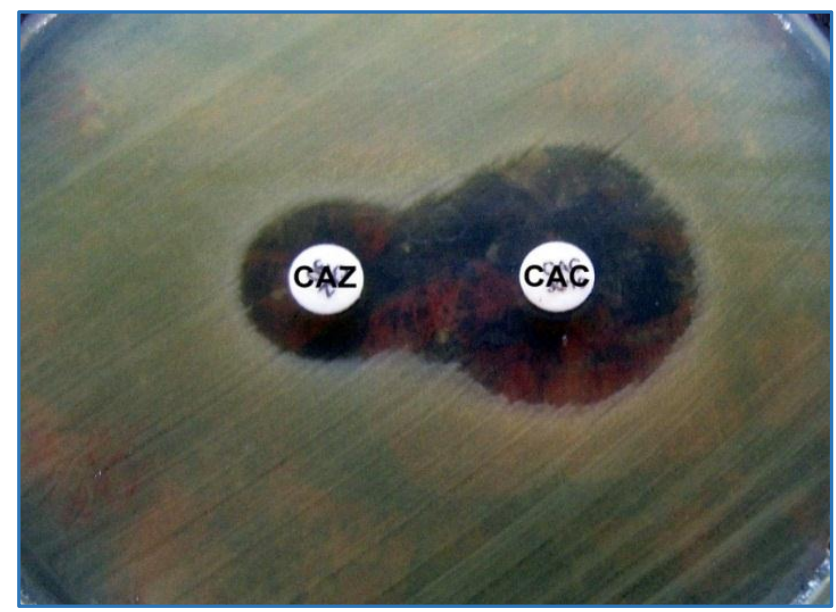

Figure 1. Extended Spectrum Beta-Lactamase Test

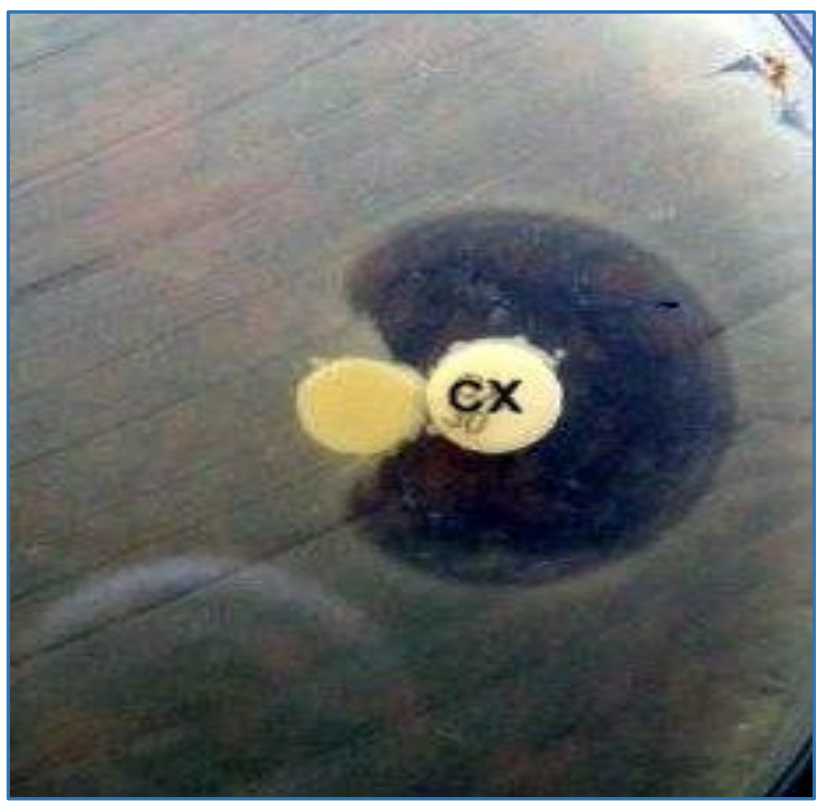

Figure 2. Amp-C Disc Test

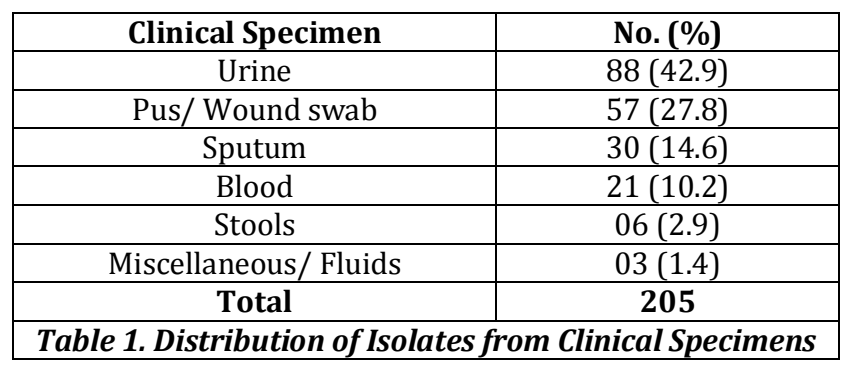

\begin{tabular}{|c|c|c|c|}
\hline Organism & $\begin{array}{c}\text { Total No. } \\
\text { of } \\
\text { Isolates }\end{array}$ & $\begin{array}{c}\text { ESBL Screen } \\
\text { Test Positive } \\
\text { No. }\end{array}$ & $\begin{array}{c}\text { ESBL } \\
\text { Confirmatory } \\
\text { Test Positive } \\
\text { No. (\%) }\end{array}$ \\
\hline Escherichia coli & 87 & 70 & $44(50.6)$ \\
\hline Acinetobacter spp. & 31 & 24 & $08(25.8)$ \\
\hline $\begin{array}{c}\text { Klebsiella } \\
\text { pneumoniae }\end{array}$ & 26 & 13 & $12(46.1)$ \\
\hline
\end{tabular}

\begin{tabular}{|c|c|c|c|}
\hline Pseudomonas spp. & 25 & 21 & $14(56)$ \\
\hline Salmonella typhi & 13 & - & - \\
\hline Enterobacter spp. & 6 & 2 & - \\
\hline Proteus spp. & 5 & 4 & $01(20)$ \\
\hline Vibrio cholerae & 5 & - & - \\
\hline Providencia spp. & 3 & 1 & - \\
\hline Citrobacter spp. & 2 & - & - \\
\hline Shigella spp. & 2 & - & - \\
\hline Total & $\mathbf{2 0 5}$ & $\mathbf{1 3 5}$ & $\mathbf{7 9}(38.5)$ \\
\hline $\begin{array}{c}\text { Table 2. Prevalence and Distribution of ESBL producing } \\
\text { Gram-Negative Clinical Isolates }\end{array}$
\end{tabular}

\begin{tabular}{|c|c|c|}
\hline Organism (n) & $\begin{array}{l}\text { Amp-C Screen } \\
\text { Test Positive }\end{array}$ & $\begin{array}{l}\text { Amp-C Disc Test } \\
\text { Positive No. (\%) }\end{array}$ \\
\hline Escherichia coli (87) & 19 & $10(11.4)$ \\
\hline Acinetobacter spp. & 19 & $14(45.1)$ \\
\hline Klebsiella spp. (26) & 06 & $05(19.2)$ \\
\hline $\begin{array}{l}\text { Pseudomonas spp. } \\
(25)\end{array}$ & 21 & $02(8)$ \\
\hline Enterobacter spp. (6) & 02 & $01(16.6)$ \\
\hline Proteus mirabilis (5) & 03 & - \\
\hline Providencia spp. (3) & 01 & - \\
\hline Total (205) & 71 & 32 (15.6) \\
\hline \multicolumn{3}{|c|}{$\begin{array}{c}\text { Table 3. Prevalence and distribution of Amp-C producing } \\
\text { Gram-Negative Clinical Isolates }\end{array}$} \\
\hline
\end{tabular}

\section{DISCUSSION}

Existence of multiplicity of resistance mechanism in gramnegative isolates remains a gray area for most of the clinical microbiologists. Despite the discovery of ESBLs and Amp-C beta-lactamases at least a decade ago, there remains a low level of awareness of their importance and many clinical laboratories have problems in detecting ESBLs and Amp-C beta-lactamases. 12 Organisms over expressing Amp-C $\beta$ lactamases are a major clinical concern, because these are usually resistant to all beta-lactam drugs except for cefepime, cefpirome and carbapenems. Phenotypic variations in the bacterial expression of plasmid encoded Amp-C mediated resistance have to be addressed cautiously. The accurate detection of plasmid mediated Amp-C is important to improve the clinical management of infection and to provide sound epidemiological data. 13

The isolation of ESBL in the present study is higher $38.5 \%$. This was similar to the ESBL isolation rates noted in different parts of the country (28 - 84\%).14-19 The isolation rate of ESBLs was lower $(18.7 \%)$ in Vinta Rawat et al. The higher isolation of ESBL in our study might be because of injudicious usage of extended spectrum beta-lactamase in our hospital and can be avoided by adopting appropriate infection control measures. The limitation of this study being the lesser sample size. The present study reveals Escherichia coli $(50.6 \%)$ and Pseudomonas aeruginosa (56\%) as the major ESBL producers followed by Klebsiella pneumoniae (46.1\%) and Acinetobacter spp. (25.8\%). Many laboratories have adopted CLSI guidelines and only attempted to detect ESBLs in Escherichia coli, Klebsiella pneumoniae, Klebsiella oxytoca and Proteus mirabilis. ${ }^{11}$ Since ESBL genes are transmissible, it is important that ESBLs be tested for other organisms in hospital and long-term care facility patient population where ESBLs are encountered.

Amp-C disk test detected Amp-C beta-lactamase in 32 $(15.6 \%)$ isolates with highest incidence in Acinetobacter spp. (45.1\%) followed by Klebsiella pneumoniae (19.2\%), 
Enterobacter spp. (16.6\%) and Escherichia coli (11.4\%). The occurrence of Amp-C beta-lactamase (15.6\%) in the present study was lower than that of Manoj Kumar Singh et al $(17.7 \%)^{20}$ and Manchanda et al (20.7\%). ${ }^{5}$ Vinita Rawat et al $(20.8 \%),{ }^{19}$ Nevine Fam et al $(28.3 \%)^{17}$ and Mohammad Parveen et al (47\%), ${ }^{2}$ but was higher than Singhal et al (8\%) ${ }^{12}$ and Sasirekha Bakthavatchalu et al (5.4\%.) ${ }^{18}$

Carbapenemase producing Pseudomonas aeruginosa and Acinetobacter spp. may be intrinsically resistant or have acquired resistance to antibiotics due to permeability barrier of the cell surface, multidrug efflux pumps and production of beta-lactamases (Amp-C and ESBL). Because of the production of multiple beta-lactamases by these two organisms and given the fact that Metallo-Beta-Lactamase (MBL) production will hydrolyse all classes of beta-lactams, it can also affect the detection of Amp-C enzyme and ESBL. In our study, Amp-C and ESBL production in Pseudomonas aeruginosa was $8 \%$ and $56 \%$ and Acinetobacter spp. showed $45.1 \%$ and $25.8 \%$. The comparison between studies becomes difficult, as the patient population in particular centres and the methods of study differ.

The co-existence of ESBL and Amp-C was found in 9 (4.4\%), in $5(5.7 \%)$ of E. coli and $4(15.3 \%)$ of Klebsiella pneumoniae. This co-existence could be due to dissemination of plasmid encoding both Amp-C and ESBL enzymes among Enterobacteriaceae and thus might give false negative tests for the detection of ESBLs. In such situations, it is desirable to develop an ESBL detection test that includes a substrate displaying a higher degree of resistance to Amp-C enzymes like cefepime. Singhal $\mathrm{S}$ et $\mathrm{al}^{12}$ observed the co-existence phenomenon in two (1\%) isolates (one each of Klebsiella spp. and E. coli), Manoj Kumar Singh RK et al 20 in $5 \%$ and $8 \%$ of isolates of Sinha $P$ et $\mathrm{al}^{21}$ showed coexistence. The only $\beta$ lactam active against co-Amp-C and ESBL producers are carbapenems; however, recently resistance to carbapenems has been increasing which is mostly due to the production of MBL.

Cefoxitin resistance can be used to screen isolates for detecting possible Amp-C $\beta$-lactamase production. But lack of permeation of porins has also been reported as one of the resistance mechanisms of cefoxitin in Amp-C nonproducers. ${ }^{22}$ Production of multiple beta-lactamases by clinical isolates has tremendous therapeutic consequences and poses a significant clinical challenge if it remains undetected. In the present study, occurrence of Amp-C and ESBL producers were more commonly seen in clinical specimens from admitted patients, thus shows its nosocomial importance. Although, many phenotypic methods are available for detection of ESBL and Amp-C, gene localisation by genotypic characterisation is considered as gold standard which helps us for epidemiological purpose. Genotypic characterisation could not be carried out in our centre.

\section{CONCLUSION}

$38.5 \%$ and $15.6 \%$ of total Gram-negative bacilli in our hospital were found to be ESBL and Amp-C producers respectively. Screening and combined disk tests were effective for ESBL detection. Confirmatory tests that detect cephamycin hydrolysis include the Amp-C disk test and the three-dimensional test. These confirmatory tests based on the detection of cephamycin hydrolysis or Amp-C inhibition will distinguish Amp-C beta-lactamases from ESBLs and porin mutations. Amp-C disk test is simple, easy to perform and interpretation requires less expertise for the rapid detection. Adoption of this test would make it possible to learn more about the clinical implications of Amp-C ß-lactamases and to contain the spread of organisms possessing this resistance mechanism. The limitation of this study was that genotypic studies based on these results could not be carried out in our setup.

\section{REFERENCES}

[1] Rajani E, Sherwal BL, Anuradha. Detection of extended - spectrum $\beta$ - lactamases in Amp C $\beta$ lactamases- producing nosocomial Gram -negative clinical isolates from a tertiary care hospital in Delhi, India. Indian J for the Practicing Doctor 2008;4(6):19.

[2] Parveen MR, Harish BN, Parija SC. AmpC Beta lactamases among gram negative clinical isolates from a tertiary hospital, South India. Braz J Microbiol 2010;41(3):596-602.

[3] Shahid M, Malik A, Agrawal M, et al. Phenotypic detection of extended-spectrum and AmpC betalactamases by a new spot-inoculation method and modified three-dimensional extract test: comparison with the conventional three-dimensional extract test. J Antimicrob Chemother 2004;54(3):684-7.

[4] Thomson KS. Extended-spectrum- $\beta$ lactamase, AmpC and Carbapenemase Issues. Journal of Clinical Microbiology 2010;48(4):1019-25.

[5] Manchanda V, Singh NP. Occurrence and detection of AmpC - $ß$-lactamases among Gram-negative clinical isolates using a modified three-dimensional test at Guru Tegh Bahadur Hospital, Delhi, India. J Antimicrob Chemother 2003;51(2):415-8.

[6] Bagali SO, Peerapur BV. Detection of AmpC Betalactamases among Escherichia coli isolates at a tertiary care hospital in Karnataka. Al Ameen J Med Sci 2013;6(1):85-7.

[7] Black JA, Moland ES, Thomson KS. AmpC disk test for detection of plasmid-mediated AmpC $\beta$-lactamases in Enterobacteriaceae lacking chromosomal AmpC $\beta$ lactamases. J Clin Microbiol 2005;43(7):3110-3.

[8] Crichton PB. Enterobacteriaceae: Escherichia, Klebsiella, proteus and other genera. In: Collee JG, Fraser AG, Marmion BP, et al. eds. Mackie \& McCartney Practical medical microbiology. $14^{\text {th }}$ edn. Edinburgh, UK: Churchill Livingstone 1996: p. 36184.

[9] Bauer AW, Kirby WN, Sherri JC, et al. Antibiotic susceptibility testing by a standardized single disk method. Am J Clin Pathol 1996;45(4):493-6.

[10] Clinical Laboratory Standards Institute (CLSI). Performance standards for antimicrobial disk susceptibility test. 8th ed. Approved standards, M2A8, Wayne, PA, USA. 2003.

[11] Agarwal P, Ghosh AN, Kumar S, et al. Prevalence of extended spectrum beta-lactamases among Escherichia coli and Klebsiella pneumoniae isolates in a tertiary care hospital. Indian J Pathol Microbiol 2008;51(1):139-42. 
[12] Singhal S, Mathur T, Khan S, et al. Evaluation of methods for AmpC $\beta$-lactamases in gram negative clinical isolates from tertiary hospitals. Indian J Med Microbiol 2005;23(2):120-4.

[13] Hanson ND. AmpC beta-lactamases: what do we need to know for the future? J Antimicrob Chemother 2003;52(1):2-4.

[14] Basavaraj MC, Jyothi P, Peerapur BV. The Prevalence of ESBL among Enterobacteriaceae in a tertiary care hospital of North Karnataka, India. J Clin Diagn Res 2011;5(3):470-5.

[15] Chaudhuri BN, Rodrigues C, Balaji V, et al. Incidence of ESBL producers amongst Gram-negative bacilli isolated from intra-abdominal infections across India (based on SMART study, 2007 data). J Assoc Physicians Ind 2011;59:287-92.

[16] Das A, Ray P, Garg R, et al. Extended spectrum beta lactamase production in gram-negative isolates from cases of septicaemia. In: Proceedings of Silver Jubilee Conference. New Delhi: All India Institutes of Medical Sciences 2001: p. 21-5.

[17] Fam N, Gamal D, El Said M, et al. Detection of plasmid-mediated AmpC Beta-Lactamases in clinically significant bacterial isolates in a research institute hospital in Egypt. Life Science Journal 2013;10(2):2294-304.
[18] Bakthavatchalu S, Shakthivel U, Mishra T. Detection of ESBL among ampc producing enterobacteriaceae using inhibitor-based method. The Pan African Medical Journal 2013;14:28. doi:10.11604/pamj.2013.14.28.1347.

[19] Rawat V, Singhai M, Verma PK. Detection of different beta-lactamases and their co-existence by using various discs combination methods in clinical isolates of enterobacteriaceae and pseudomonas spp. Journal of Laboratory Physicians 2013;5(1):21-5.

[20] Singh MRK, Pal NK, Banerjee M, et al. Surveillance on extended spectrum $\beta$-lactamase and AmpC $\beta$ lactamase producing gram negative isolates from nosocomial infections. Archives of Clinical Microbiology 2012;3:3:1. doi: 10.3823/252

[21] Sinha P, Sharma R, Rishi S, et al. Prevalence of extended spectrum beta lactamase and AmpC beta lactamase producers among Escherichia coli isolates in a tertiary care hospital in Jaipur. Indian J Pathol Microbiol 2008;51(3):367-9.

[22] Pangon B, Bizet C, Bure A, et al. In vivo selection of cephamycin-resistant, porin-deficient mutants of Klebsiella pneumoniae producing TEM-3 beta lactamase. J Infect Dis 1989;159(5):1005-6. 